\title{
NOTES ON ATTELABUS RHOIS AND PARASITE.
}

BY C. A. FROST, SOUTH FRAMINGHAM, MASS.

During July, 1904, while collecting Coleoptera along the edge of a large tract of alders (Alnus incana) that covers a rocky hillside in the town of Wales, Maine, I found this beetle occurring in great abundance. As many as a dozen of their rolls or nests in various stages of freshness could be counted on a single small cluster of bushes while the ground was littered with the dried, brown cylinders that had fallen. This was on the 15th of the month and five miles away at Monmouth I was unable to find a single specimen. On the 20th of June of the following year a few nests were found at Wales and on the 30th they were quite plentiful in a few places at Monmouth. While I have taken only two or three specimens of the adult weevil in Massachusetts during the last five years, similar nests, each containing a similar egg, have been found in numbers at Framingham, Mass., on the hazel (Corylus americana).

In Maine the adult insect feeds upon the alder leaves, eating long narrow holes between the veins in a manner that gives the leaves a very peculiar and distinctive appearance. Most of the small cross veinlets are eaten off leaving the ends sticking into the hole and giving it a ragged or notched outline, while here and there a veinlet is left untouched.

Dr. A. S. Packard, in 1872, published an article entitled Embryological Studies on Hexapodous Insects, III Memoir Peabody Academy of Science, in which he gives a few observations on the habits of this species of Attelabus. Therefore, while the following notes on the construction of the egg roll, or nidus, are not entirely new, there may be a few more points worthy of consideration.

The work of preparing and rolling the nidus, so far as shown by my observations, is done entirely by the female weevil. She selects a leaf and cuts a slit on each side of the petiole, extending from the blade to the mid-rib at a short distance from the base of the leaf. This cutting leaves a triangular piece of the blade attached to the petiole while the major part of the leaf is held only by the mid-vein at the point where the cuts converge. This point is next attacked. The front legs are thrust down through the two cross cuts and clasped around the mid-vein, while the hind legs are spread far apart and extended out on the blade of the leaf. Then pushing downward with the hind feet and pulling upward with the front legs, she bites the mid-vein until it droops and hangs at right angles to the stem. The operation is not always done in this way, however, for one female was observed standing on the petiole while at 
work, and, not using the legs at all, relying upon the weight of the leaf to bring it down when sufficiently cut through. One female was timed while cutting the midvein; she completed the work in four minutes.

As soon as the leaf falls into a pendent position, the weevil begins travelling over the upper (in every case observed) surface, biting it at every step and at the same time drawing it into a wrinkle by the two sharp spurs at the tarsal ends of the anterior tibiae. The path over the leaf was in many cases parallel to the edge but became very irregular after two or three rounds had been made. Leaves examined at this stage show, on holding to the light, the course of the weevil by a series of small holes. The time required by one female to finish the upper side was about fifteen minutes of continuous work.

In every case observed the mid-vein was the first point to be attacked on the under side of the leaf; and the cross-veins showed by the brown spots plainly visible on the more wilted leaves that the biting was done mostly on them. This may be on account of the thick pubescence on the under side of the alder leaf being shorter and less troublesome on the veins. They may be bitten their whole length or only a short way from the mid-vein.

As soon as the under side is completed, which does not take as long as the upper side, copulation often takes place, although cases were noticed when this occurred while the preparation of the upper side of the leaf was in progress. Dr. Packard states in the article previously referred to, "I once saw a female pick up a leaf with her jaws, then stop, and run back to receive the embraces of the male, and then resume her work. In another case I saw the sexes unite after a roll had been half made, so that it is probable that union occurs several times at short intervals, as I have observed to be the case with G. polygoni." When the male appears on the leaf he takes a position on the petiole, or sometimes, as Dr. Packard mentions, on an adjoining one. If alarmed, he sits nearly upright with the head and snout raised as if scenting an enemy and remains motionless for a long time. The least jar of the bush, unless the wind be blowing strongly, or a quick movement on the part of the observer, should he be too near, will often cause the male to drop to the ground from this apprehensive attitude. The female is not so easily disturbed and observations were frequently made with a hand lens of about an inch focus without attracting her attention. A slight jar would generally cause her to suspend operations for a moment or so, but there would be very little fear exhibited. In one instance the male was observed to run down the leaf, around the female, and back again as if inspecting her work; and after she began to roll the leaf he became very excited and kept moving continually. After the biting is completed, the female, sitting upright, oviposits on the tip of 
the leaf. In nearly every nest examined the egg was placed on the under or pubescent side but the tip had been bent back against the smooth surface and the egg had become the very center of the roll. Out of the dozens of nests opened only one was found to have two eggs, all the rest contained but a single, yellow, translucent egg. Dr. Packard states, "Before the leaf is entirely rolled, she deposits a single egg, rarely two, in the middle, next the mid rib, in a little cavity, where it lies loose." He also describes the egg as being nearly spherical, though a little longer than thick, .04 of an inch long, by .03 of an inch in diameter.

The leaf, by the time oviposition has been completed, has become very much wrinkled and wilted so as to be easily manipulated in any way. It may be the object of the biting process to accomplish this result more quickly by weakening the leaf by cutting so many small fibres and causing the sap to evaporate more rapidly.

The female with her snout and fore legs now crumples up the tip of the leaf with the egg in the center for the beginning of the roll, at the same time folding the leaf so as to bring the two smooth halves together. It is then rolled up with the mid-vein as one edge of the roll and the doubled serrated edge as the other. The rolling is done by the tibial spurs and the jaws which are much stouter and thicker than those of the male. When the serrated edge of the roll becomes twisted at times like the top of a paper bag, the snout and jaws are thrust into the end of the roll until the head is out of sight, and the protruding edges are tucked carefully within while the legs are used to pull the edges of the roll together and hold them for several seconds in this position. One weevil was timed from the commencement of the biting and wrinkling process until she stood on the completed roll taking a rest; it was almost exactly one hour. This seemed a shorter time than usual which may be accounted for by the fact that there had been no interruptions.

During my observations in 1904, at Wales, while the leaf was being wrinkled, there appeared from two to six small, green-bodied hymenoptera with conical abdomens on each leaf. They either followed the female weevil at a short distance or remained at rest on different parts of the leaf. The male weevil would, apparently, make efforts to drive them away, once even pushing one from the leaf with his snout, but no attempt to bite them was observed. A leaf was picked on which a weevil had just oviposited and on which were four of these hymenoptera; while held in the hand two of them evidently oviposited and immediately left. No egg could be seen.

At Monmouth in 1905, not more than one of these parasites could be found attending a weevil, and then only after the rolling process had been started. The insect ran about or rested on the upper part of the leaf. When ovipositing, it generally selected a place on the side of the roll that was about to be covered by the next fold; 
rising to the full length of its legs, it would then be able to insert the end of its ovipositor, and it was thrust down into the roll sometimes by twisting and turning the body as if the entrance was rather difficult. When the ovipositor was in full length, the center of the body was touching the leaf and the tip of the abdomen pointing up into the air, making nearly a right angle with the head and thorax. This operation occupied only a second or two, and one parasite was seen to oviposit, or, at least, to thrust the ovipositor down into the same roll sixteen times during the formation of the nest. The female weevil did not notice the parasite even when it was within a quarter of an inch of her. The male weevil was patrolling the roll while the parasite was ovipositing and only once did he seem to interfere with its work. A sudden shower stopped these observations and another favorable opportunity did not occur.

Specimens of the weevil and parasite were sent to Washington where Dr. Chittenden identified the weevil as Attelabus rhois, Boheman, and Dr. Ashmead pronounced the parasite to be Omphale (Euderus) elongatus, Ashmead. It had not been recorded before as an enemy of the weevil.

A number of alder rolls were brought from Maine in 1904 and opened at different dates. The following notes were made:

On July 30th one was found to contain a yellowish, shrunken larva, bent at right angles in the middle, and apparently just alive. There was also found in this roll a smaller white larva, slim and straight, about $1 \mathrm{~mm}$. in length. A large yellow larva in plump condition was found in another roll and no parasite. This larva was 2.5 mm. long and covered with whitish hairs which were longer and pointing forward on the thoracic segments. The head and jaws were of a chestnut color. It was flattened beneath and seemed incapable of straightening itself from its curled-up position.

On September 4th I opened all the remaining alder rolls and found the inmates dead probably from mould. In one nest were three small larvae, apparently Hymenopterous.

The investigations of the habits of this weevil has brought out the peculiar fact that while the weevil feeds and makes its nest upon the alder (Alnus incana) in Maine, in Massachusetts, as far as I have yet been able to discover, it makes its rolls from the leaves of the hazel (Corylus americana). I found one instance where it had fed on the leaves of this species of hazel in Maine, but the bush was growing beside an infested alder and the branches were intermingled. I have never taken the adult weevil on the hazel in Massachusetts, in fact, during the past seven years I have taken but two specimens in this state.

On August 6th, 1904, I secured a dozen or more nests from the hazel in Framing- 
ham. Of the two examined at this time, one contained a very small larva and the other was empty. One of the alder rolls from Maine was opened at the same time and found to contain a much larger larva. On September 4th three of the hazel rolls were opened and several small, yellowish white, footless larvae were found between the folds of the roll, and a larger larva in the center of the roll. These small larvae were about $1 \mathrm{~mm}$. in length. There were several of the rolls that were fastened together by a web at this time and an examination showed that a dark, smooth, Lepidopterous larva had been feeding on the rolls and leaving a mere shell with a hole in the side. The rolls were also covered with small white mites. On February 4th two hazel rolls were opened and one larva about $6 \mathrm{~mm}$. long was found in each. They were similar to the one found in the alder roll on July 30th, but larger. The inside of the roll was filled with fine dust leaving only two or three of the outside folds intact.

A large number of alder and hazel rolls were collected in 1905 and kept until the next summer when, in June, nearly every alder roll yielded an adult weevil and six or more were obtained from the hazel rolls. The latter were, however, not fully developed, perhaps on account of being kept too dry. Not being able to detect any marked difference between the alder and the hazel specimens, I sent several of each to Mr. Frederick Blanchard who very kindly examined them and wrote me that he was unable to discover any difference between them, but on account of the condition of the specimens he could hardly consider this as being conclusive.

Assuming that there is only one species, I am unable to offer any explanation why the food plant should differ in the two localities. It cannot be attributed to the abundance of one species of plant in one locality and its scarcity in the other because at Monmouth, Maine, the two species of shrubs grow side by side; at Wales, Maine, I do not remember seeing any hazel, certainly not in the immediate vicinity of the infested alders; at Framington, Mass., in one locality the alder is the more abundant and in another place the hazel patch is isolated.

Besides the article by Dr. Packard, previously referred to, the following papers. on the habits of the species of the Attelabidae have been brought to my attention by Mr. Blanchard: Notes on Attelabus Bipustulatus by Miss Mary Murtfeldt, Can. Ent. v. IV, 1872, p. 143. Attelabus Bipustulatus, Fab. Theory of Oviposition and Construction of Nidus; Miscellaneous Notes by A. Arsene Girault, Ent. News, v. XV, pp. 189-193. A brief mention of Attelabus rhois on the hazel in the Can. Ent. v. XXIII, pp. 21 and 26. Cambridge Natural History of Insects, pt. II, p. 29, gives an account of the operations of Rhynchites betulae, an European leaf roller, and refers to more extensive remarks by German writers. 


\section{Sexual Characters.}

Male.- Apical angles of the beak prolonged, acute; beak longer before the eyes and slenderer than in the female causing the eyes to appear slightly more prominent. By careful comparison the antennae will be found to be stouter, with the club larger and the joints more loosely articulated than in the female. Head narrower behind the eyes than the female, with a prominent median carina extending from the posterior line of the eyes to the occiput, carina often black and sometimes with a black area surrounding it. Prothorax more narrowed in front than in the female. Anterior tibiae arcuately curved, slender, equal in length to one and one half times the length of the prothorax; all the tibiae are armed at the distal end with a single curved hook, the inner or posterior one wanting; all tibiae with two rows of serrations on the inner edge. The anterior femora, viewed laterally, are straight on the upper edge - that is, the clavate portion is asymmetrical; the femora are longer and the coxae longer and stronger than in the female. The prosternum is not so deeply excavate (or emarginate) in front, and with an evident depression before the coxae.

Female.- Apical angles of the beak only very rarely prolonged; beak shorter and stouter, broader and thicker at the apex than in the male. Head with the carina usually replaced by a smooth median line, sometimes with a black area as in the male. Prothorax broader in front. Anterior tibiae equal to or slightly exceeding the length of the prothorax; the inner row of serrations on the inner edge of the tibiae are more prominent than in the male; first serration sometimes half the length of the inner hook of the tibia. In the females all the tibiae are armed at the distal ends with two hooks curving inward toward the body, the outer one of which is longer and stouter. All the femora are symmetrically clavate. Prosternum emarginate or excavated in front nearly to the coxae.

I am indebted to Mr. Frederick Blanchard for pointing out the characters of the prosternum, and antennae, and for informing me that the serrations of the tibiae are disposed in two rows. He has also very kindly verified the other characters from specimens in his cabinet.

My few specimens of Attelabus analis and bipustulatus agree with rhois in the sexual difference of the tibial hooks, and Mr. Blanchard writes me that his specimens of analis, nigripes, and bipustulatus all differ in the same manner sexually. He also says regarding the two last mentioned species, "It seems not to have been noticed that in Attelabus nigripes and bipustulatus the beak is obliquely truncate beneath and that the gular peduncle is obliquely compressed each side, converging to a distinct 
angle which is still more marked and almost dentiform, when viewed laterally. This is most distinct in the females of bipustulatus."

I have none of the former species, but my few females of the latter show very clearly the above characters as he describes them.

In connection with this subject, attention is called to an error in the Rhynchophoridae of America North of Mexico, LeConte and Horn, p. 10; under Attelabus analis the sex marks should be reversed in the description of the sexual characters. Also in the Family characters on the same page the statement "armed at the tip with two strong hooks" is misleading and should be qualified, because this, as it now reads, applies only to the females and not to the males which have only one hook. This latter statement appears also in the "Classification" and should be restricted likewise.

\section{THE HALICTIDAE OF SOUTHERN MAINE.}

BY JOHN H. LOVELL, WALDOBORO, MAINE.

WHILE comparatively few new species of bees have been found in southern Maine, the described species very frequently differ in a greater or less degree from southern and western material. This is especially true of the species of Halictus, which present variations in the descriptive characters in consequence of which it is difficult in many instances to determine whether they are of varietal or specific importance. H. provancheri D. T. exhibits only slight differences, but the female of $\mathrm{H}$. lerouxii Lep. is narrower than the Illinois representative of this species, and has the pubescence of the thorax above ochreous instead of grayish-white. H. craterus is a new species allied to $H$. similis and $H$. discus. H. arcuatus var. parisus, especially the male, differs so widely from typical material that it might well be regarded as a new species. The local specimens of $\mathrm{H}$. foxii closely resemble the Illinois form and at most constitute only a race; while $\mathrm{H}$. divergens sustains a nearly similar relation to $\mathrm{H}$. quadrimaculatus. Maine specimens of $\mathrm{H}$. pilosus are usually smaller than those from Indiana; while $\mathrm{H}$. pilosus var. leucocomus occupies an intermediate position between this species and $\mathrm{H}$. pruinosus, and is usually mistaken for the latter species. $H$. hortensis is near to H. sparsus, but it may be separated from specimens of the latter species received from Pennsylvania by its larger size, and in the female by the broader and lighter-colored abdomen, and in the male by the more coarsely striated 

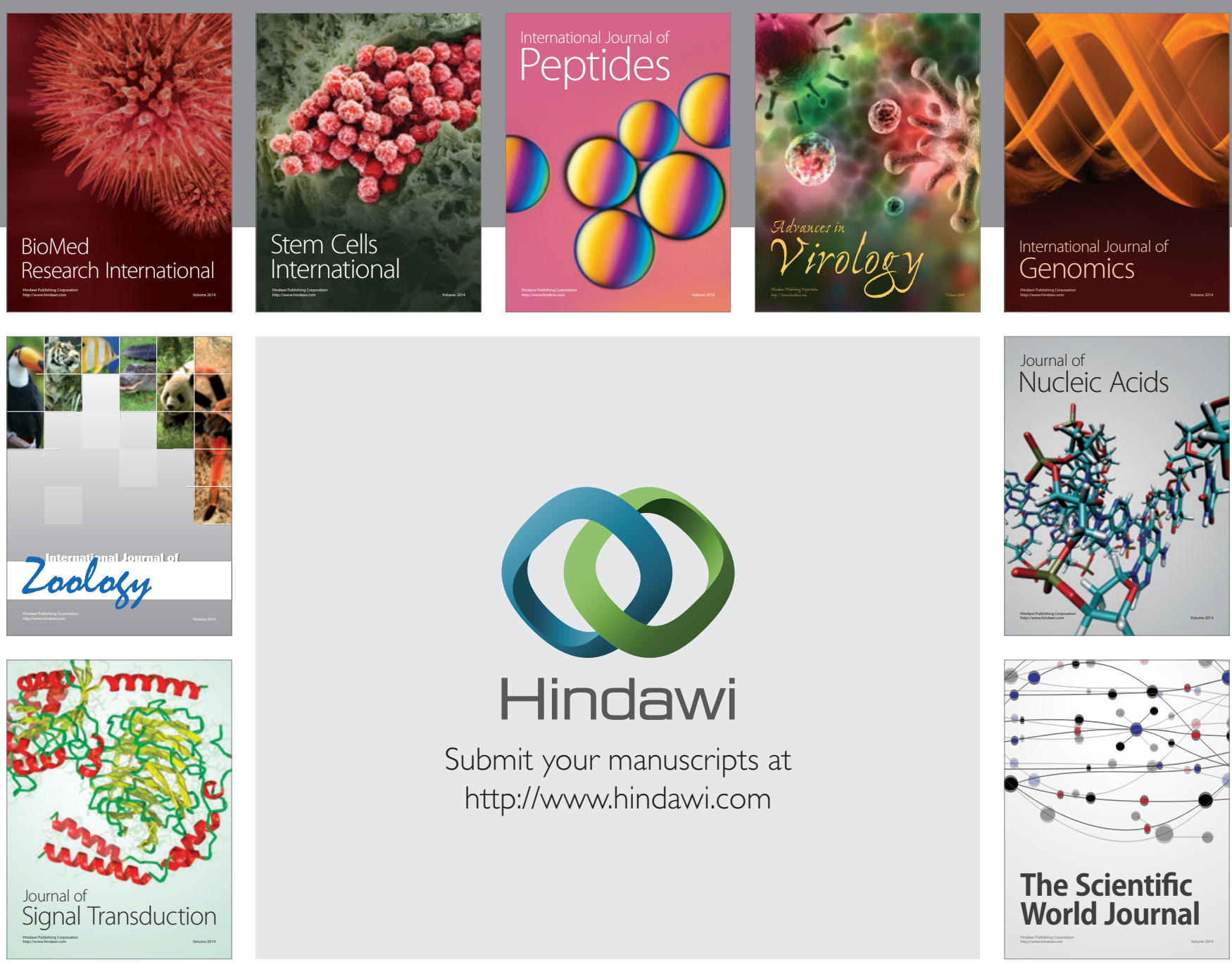

Submit your manuscripts at

http://www.hindawi.com
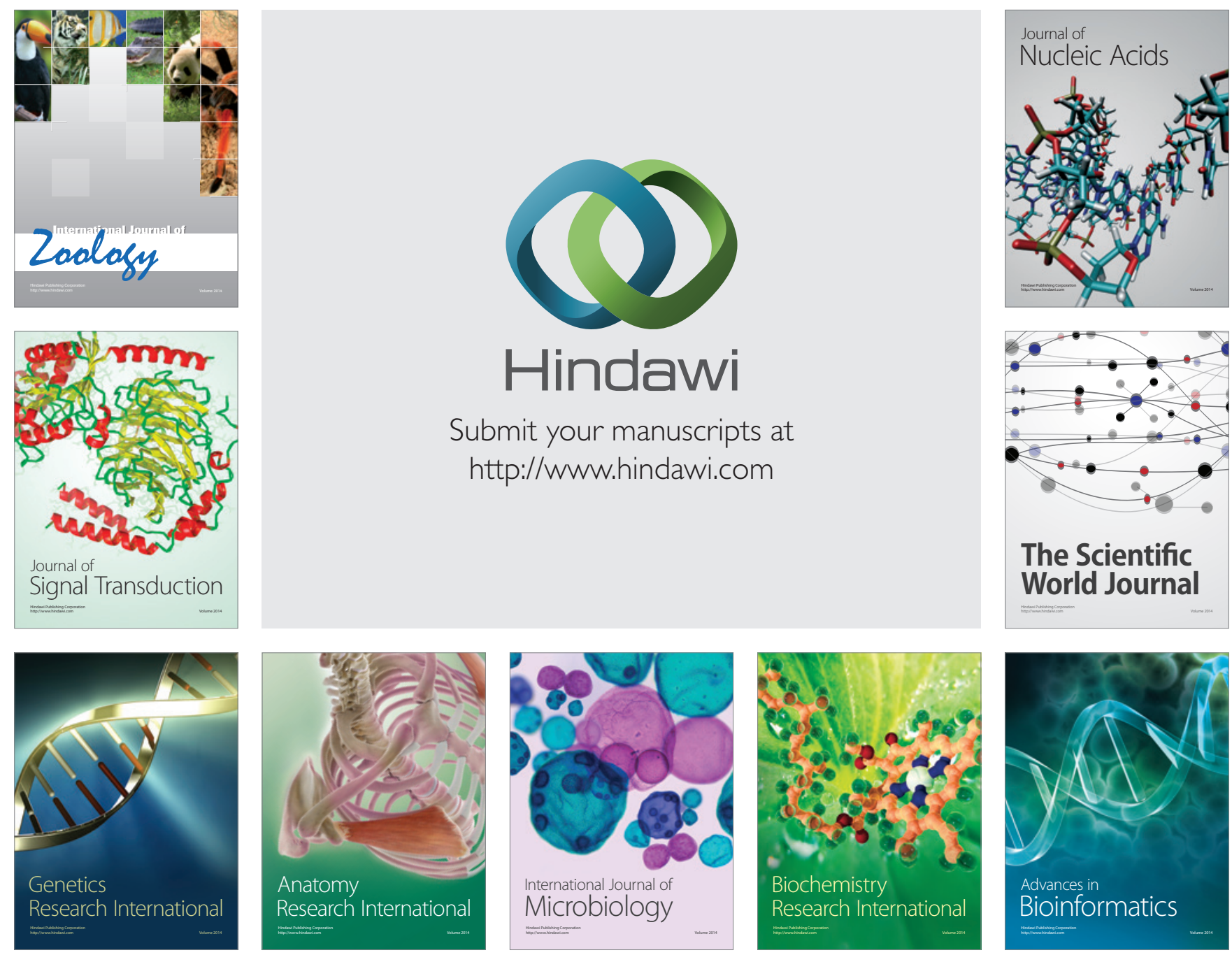

The Scientific World Journal
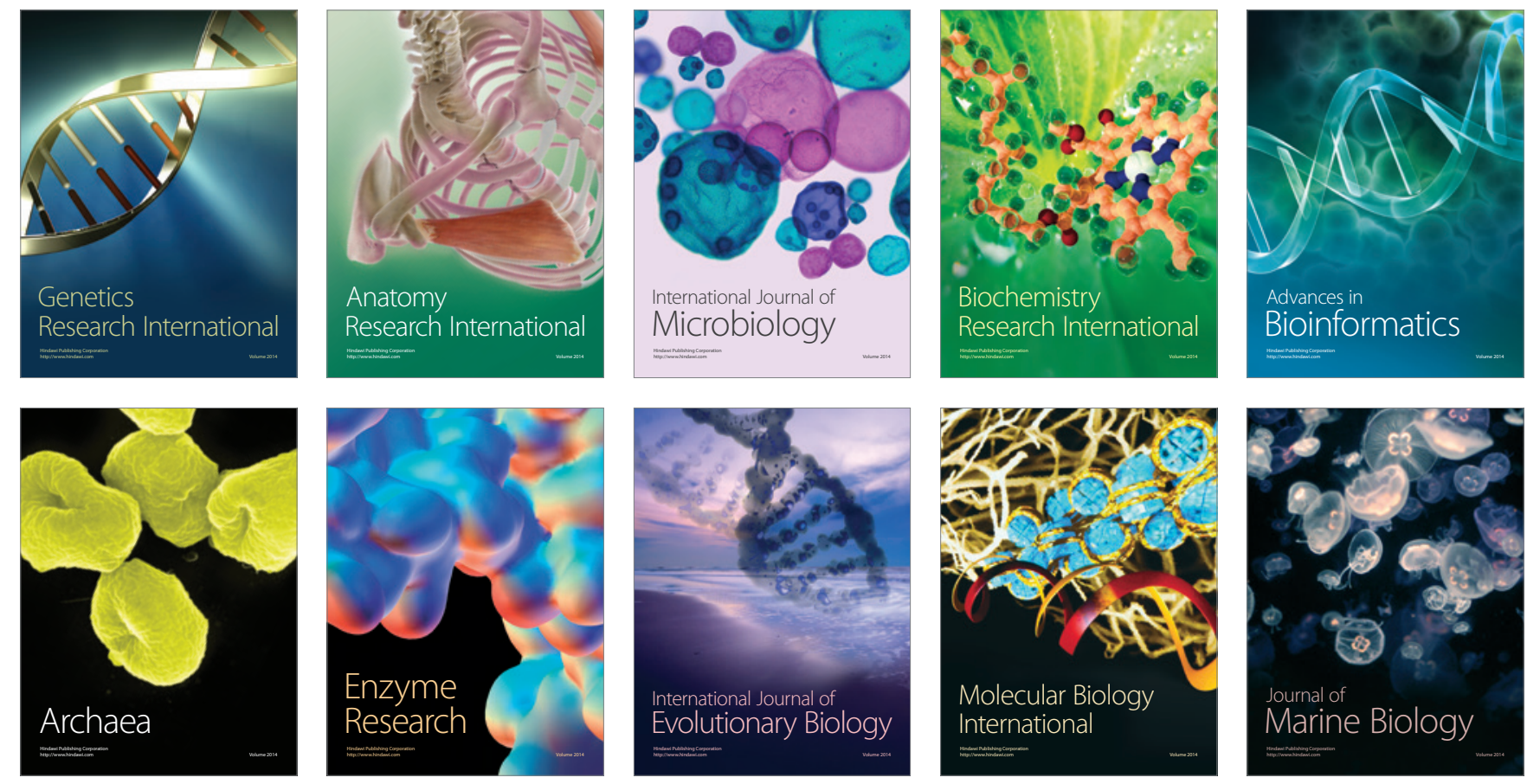